\title{
The European Union's New Framework Programme (2002-2006) and Research on Advanced Materials
}

This article is reprinted with permission from Facets 1 (3) (2002) p. 7. (C2002 International Union of Materials Research Societies. This article was written at the request of the IUMRS. It represents the opinions of the authors and does not necessarily reflect those of the European Commission.

New materials will play a prominent role in shaping society for the next decade. Research in materials science and related areas such as nanotechnology is therefore a strategic priority for Europe. The European Commission has proposed a new multiyear Framework Programme (2002-2006) for research, technology development, and demonstration (RTD). Under an initiative to create a European Research Area, this program is expected to provide a powerful tool for maintaining competitiveness and ensuring economic growth based on sustainable development.

\section{Materials Research: A Strategic Priority for Europe}

Recent decades have seen enormous technological advances due to progress in disciplines such as electronics, biotechnology, and materials sciences. These have improved the quality of life, both directly through new products and services and indirectly by creating wealth and employment. The European Union (EU) has recognized research as a future political priority, affirming that knowledge and technology are the driving forces behind economic growth and competitiveness.

In March 2000, the Lisbon Council of Research Ministers set an ambitious strategic goal for the EU: to become the most competitive and dynamic knowledgebased economy in the world, capable of sustainable economic growth with more and better jobs and greater social cohesion over the next decade. Research in materials science and emerging technologies will play an essential role in achieving this goal.

Nanotechnology and materials are emphasized by one of the seven strategic priorities for future RTD efforts. The use of nanotechnology in engineering of materials and development of new advanced materials can lead to innovative solutions for tomorrow's products and services that may revolutionize both production and business. Within the next decade, materials are expected to become more intelligent and multifunctional. They will increasingly integrate knowledge and added value, and they will perform new functions, such as increased adaptability, self-regulation, self-diagnostics, and self-repair.

Such intelligence embedded in materials should simplify devices, components, and systems. The challenge is to find new ways to improve products and manufacturing not by adding, but by taking away material. Products and processes must be reconceived to reduce the total amount of matter used. New intelligent materials should be able to fulfill multiple roles, replacing many of today's components, even complex ones. Materials should also become more ecologically efficient in the way they are produced and used, enabling recycling and reduced use of natural resources.

To develop these materials, a concerted research effort in advanced technologies is of paramount importance, particularly in the case of nanotechnology. Together with information technology and biotechnology, nanotechnology may become a catalyst for a future industrial and cultural revolution leading to huge improvements in the quality of life by offering an enormous variety of applications from electronics and information society technologies, to transportation, medicine, and pharmaceuticals, and to chemicals and chemical processing, energy, and environment.
Research philosophy is also changing. New advanced materials and emerging technologies are raising new questions for society. Scientific research increasingly affects our daily lives. Research is no longer ruled by the scientists alone but requires an open dialogue with the public that involves the contribution of all. A new approach to RTD is also needed that integrates skills, disciplines, and materials (combining inorganic, organic, and biological matter).

\section{The European Research Area and the New Framework Programme}

Recognizing the key role of RTD in materials science, the European Commission has constantly supported efforts in the field of materials and their production technologies. Since 1983, materials have constituted an integral element of the Framework Programmes. These programs have promoted cooperation and supported collaboration. The current (Fifth)

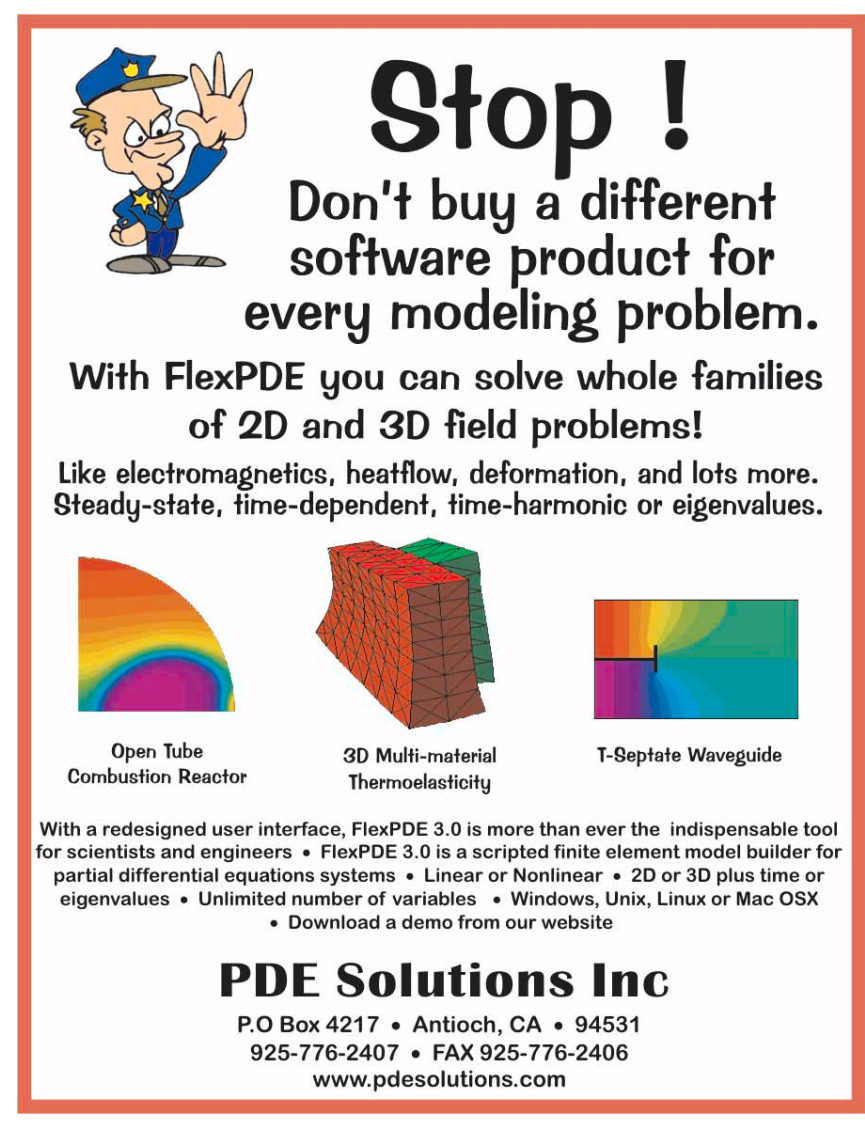

Circle No. 10 on Inside Back Cover 
Framework Programme (1998-2002) has allocated about 410 million $€$ for the "Materials and their Technologies for Production and Transformation" Generic Activity within the "Growth" Programme.

The Commission has proposed a new Framework Programme (2002-2006) - the FP6. According to procedures, the interinstitutional debate has started, and the stakeholders have taken their positions. The debate should lead to adoption of the Framework Programme in mid-2002. A trend toward longer-term, riskier research leading to radical innovation is noted.

The raison d'etre of this new Framework Programme is to help to make a reality of the European Research Area with a view to stepping up innovation in Europe, in conjunction with efforts at the national, regional, and European levels.

The new Framework Programme will be based on these principles:

- Concentrating on a selected number of priority research areas in which EU action can add the greatest possible value;

\section{Together with information} technology and biotechnology, nanotechnology may become a catalyst for a future industrial and cultural revolution...

- Defining various activities so that they can lend structure to research activities conducted in Europe through a stronger link with national, regional, and other European initiatives; and

- Simplifying and streamlining the implementation, on the basis of the intervention methods defined and the decentralized management procedures envisaged.

Seven thematic priorities have been identified. Efforts will be implemented through different types of instruments, in particular through the Networks of Excellence and Integrated Projects, capa-

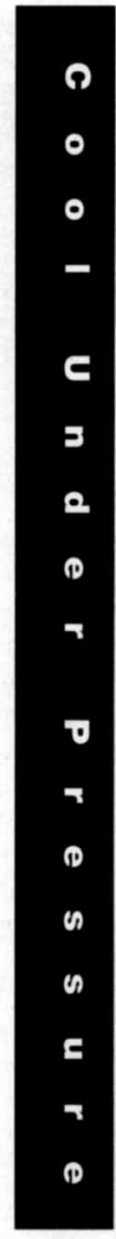

Hall Measurement System MMR's low cost, Turnkey Hall Effect Measurement System provides user programmed computer controlled measurement and data acquisition over a temperature range of $-200^{\circ} \mathrm{C}$ to $+300^{\circ} \mathrm{C}$ - without the use of liquid nitrogen. The system measures magneto resistivity, four point resistivity, sheet resistivity, sheet number, mobility, Hall coefficient, and carrier density using the Van der Pauw and Hall measurement techniques.

\begin{tabular}{|c|c|}
\hline Resistivity & $10^{-4} \mathrm{Ohm}-\mathrm{cm}$ to $10^{+13} 0 \mathrm{hm}-\mathrm{cm}$ \\
\hline Carrier Mobility & $1 \mathrm{~cm}^{2} /$ volt-sec to $10^{+7} \mathrm{~cm}^{2} /$ volt-sec \\
\hline Carrier Density & $10^{+3} \mathrm{~cm}^{-3}$ to $10^{+19} \mathrm{~cm}^{-3}$ \\
\hline
\end{tabular}

For more information about the Hall Effect Measurement System, contact Bob Paugh at 650 / 962-9620 or bobp@mmr.com. Or visit our web page at http://www.mmr.com.

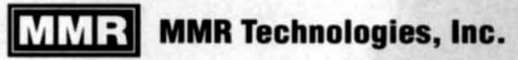

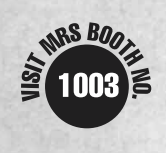

ble of exerting a particularly significant influence because of their integrating effect and the scale of the human and financial resources mobilized.

The objective of Networks of Excellence is to boost European excellence by bringing together, in a way that will last, research capacities present in the various European regions. The integrated projects, designed as large-scale activities and preferably conducted as public/private partnerships, will help mobilize the necessary resources around precisely defined objectives in terms of products and processes and in terms of scientific and technological knowledge.

The arrangements for operating the Networks and Integrated Projects will be set up following calls for proposals. They will be defined to ensure a large measure of managerial autonomy for the consortia involved. Aspects relating to innovation, infrastructure, human resources, and science/society will be considered in the way these actions are implemented.

Small- and medium-sized enterprises (SMEs), apart from participating in the Framework Programme in the context of the activities carried out in the priority thematic areas, have the possibility of using dedicated support actions for both cooperative and collective research. In support of European competitiveness and enterprise and innovation policy, these specific actions are intended to help European SMEs to boost their technological capability and develop their ability to operate on both the European and the international scale.

\section{Materials Science in the New Framework Programme}

One of the thematic areas in the FP6 is called "Nanotechnologies and nanosciences, knowledge-based multifunctional materials, and new production processes and devices," which includes themes that are recognized as some of the main strategic priorities for European research for the years to come. This priority represents a proactive response, designed to safeguard EU strengths and assets in the field of materials science and to convert weaknesses into challenging opportunities. It emphasizes the role of RTD in boosting European industrial competitiveness and sustainability.

Activities will reinforce a solid knowledge base on materials science, safeguard international leadership in strategic fields, and endeavor to bridge the innovation gap by linking industrial demand with the research world. The present lack of integration of materials and manufactur- 
ing has been identified as one of the weaknesses of European industry.

Special attention is also given to human resources. In the area of materials science, a danger exists of a shortage of human resources over the next decade. There is a need for a new breed of researchers with interdisciplinary skills who will have to work not only in but also across traditional disciplines (biology, chemistry, physics, engineering, and electronics).

Research areas will emphasize the sustainable production of new intelligent materials for multisector applications. Research will cover the entire materials lifecycle supported by long-term activities that embrace generation of fundamental knowledge, and the development of new materials together with associated technologies and tools.

For nanotechnology and nanoscience, the main objectives are to increase overall knowledge in the academic world and in industry, to promote the creation of an RTD-intensive European nanotechnology industry, and to promote the adoption of state-of-the-art nanotechnology in industry.

Long-term interdisciplinary research is expected to cover the whole spectrum from fundamental knowledge to development of new materials, novel manipulation tools, and new cutting-edge applications. A particularly strong emphasis is placed on nanobiotechnology and biomaterials. Indeed, hybrid materials and technologies-integrating biological and nonbiological entities—-show impressive potential.

\section{Final Remarks}

Future research activities funded by the EU should provide new momentum and induce an increased dynamism towards achieving the Lisbon goals. Materials science will play a key role.

An open debate throughout society will be needed, particularly in sensitive fields such as biomaterials, nanotechnology, and new materials for traditional applications. Such discussions should increase acceptance and visibility of materials science in all its applications and implications for Europe.

By addressing challenges of global relevance, European community research will benefit dramatically from an international dimension, building on existing skills and knowledge to achieve the appropriate critical mass to face international objectives.

By combining research efforts in materials and increasing impact across Europe, we will be able to contribute toward the European society of tomorrow, ensuring more, higher-quality jobs and an overall improvement in the quality of life for tomorrow's European citizens.

LUISA PRISTA AND RENZO TOMELLINI

Luisa Prista holds a degree in Mechanical Engineering, with a specialization in Applied Thermodynamics, from the University of Lisbon in Portugal. She is Head of Unit for Materials Research within the Competitive and Sustainable Growth Programme of the Research Directorate General of the European Commission covering the areas of materials and nanotechnology research. She previously worked in private engineering companies and the Swiss Federal Government, where she was appointed Head of Office for INFO-energy.
Renzo Tomellini graduated with a degree in chemistry. He is the assistant to the director of "Competitive and Sustainable Growth: Research Actions for Industrial Production" for the European Commission, with particular emphasis on international cooperation issues and research in nanotechnology. He previously worked in Italy at the Centro Sviluppo Materiali and with the related Italian steel industries as a researcher in steel and steelmaking. He has filed four patent applications, published some 30 articles, and prepared four standards on reference materials for analyses and measurements.

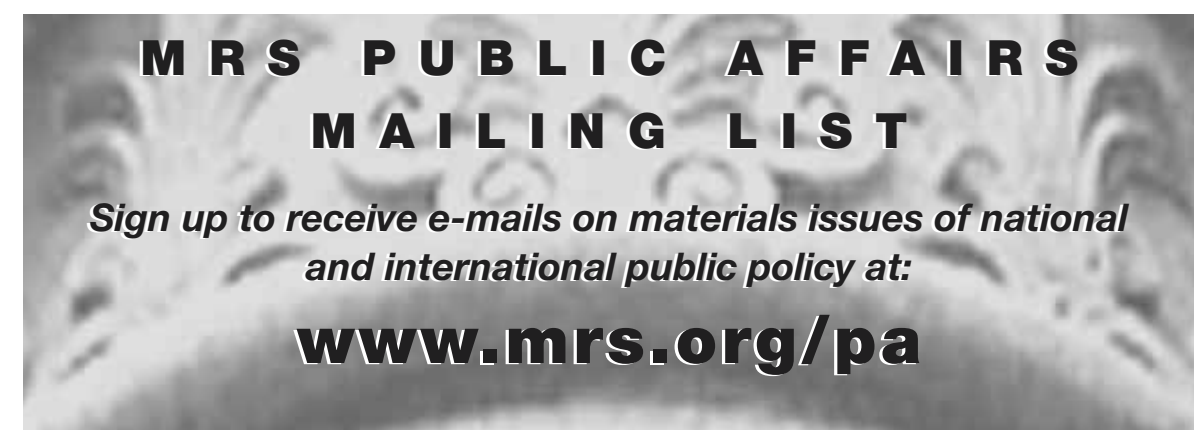

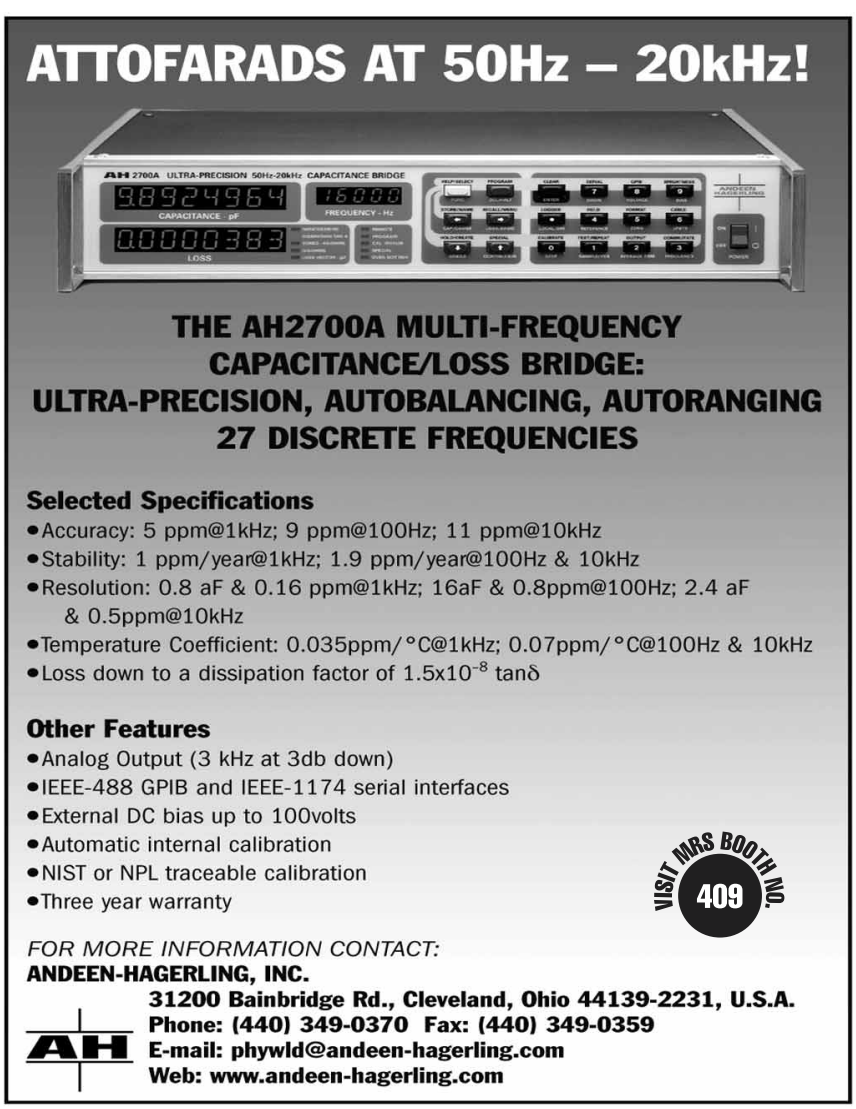

Circle No. 7 on Inside Back Cover 